\title{
Progress in Phytochemical and Bioactivities of Coffea arabica L.
}

\author{
Xiao-Jing Shen, ${ }^{a}$ Zhu-Bin Zhou, ${ }^{b}$ Fan-Qiu Nie, ${ }^{b}$ Cheng-Ting Zi, ${ }^{*, b}$ and Jiang-Ping Fan ${ }^{\star, a}$ \\ ${ }^{a}$ College of Food Science and Technology, Yunnan Agricultural University, Kunming, Yunnan 650201, China \\ ${ }^{b}$ College of Science, Yunnan Agricultural University, Kunming, Yunnan 650201, China \\ Email: zichengting@126.com (C. Z.),1993033@ynau.edu.cn (J. F.)
}

\begin{abstract}
Coffea arabica L. is a famous specie in genus caffee for medicinal treatment and diet with wide distribution and rich resources. It contains rich alkaloids, flavonoids and terpenes, which exhibited antioxidation, anti-inflammatory, antitumor, antidiabetic, live protection, and neuroprotective activities. Herein, we summarized the progress in the chemical constituents and bioactivities of $C$. arabica $\mathrm{L}$. to provide ideas for medicinal development prospects of $C$. arabica $\mathrm{L}$.
\end{abstract}

Keywords Coffea arabica L., chemical constituents, bioactivities, progress

\section{Introduction}

Coffee is one of the most important agricultural products in the world and is mainly distributed in Central and South America, Africa and South Asia. ${ }^{[1]}$ There are 124 species in genus Coffea. Among them, Coffea liberica, Coffea robusta and Coffea arabica are used to make coffee beverage. ${ }^{[2]}$ As the main region in China, Yunnan province occupies more than $99 \%$ of coffee planting. Coffea arabica Linn. (C. arabica L.) from Yunnan has been appraised as the world high quality coffee planting base by international coffee tasting experts. Coffee, as diuresis and stomach medicine, can be used to treat mental burnout and anorexia. Modern pharmacological studies revealed that $C$. arabica $L$. had the bioactivities of antioxidation, anti-inflammatory, antitumor, antidiabetic, live protection, and neuroprotective. Up to date, a total of 152 compounds involving 5 alkaloids, 25 flavonoids, 55 terpenes, 45 phenolic acids and their derivatives, 7 sterols and 10 other compounds have been isolated from this plant. In this paper, we summarized some progresses of phytochemical and pharmacological activities of $C$. arabica $L$. to provide a reference for better understanding its effective substances.

\section{Chemical Constituents}

Up to 2020, 153 compounds have been isolated from various parts of $C$. arabica L., including alkaloids, flavonoids, terpenes, sterols, phenolic acids, and other compounds.

\section{Alkaloids}

Alkaloids are typical constituents of genus Coffea. Up to date, five alkaloids have been isolated and identified from the seeds and the stems of $C$. arabica L. (Figure 1). These alkaloids were identified as caffeine (1), theobromine (2), theophylline (3), trigonelline (4) and nicotinic acid (5). ${ }^{[3,4]}$ Among them, caffeine is the highest in $C$. arabica $\mathrm{L}$. as the main active ingredient and content.
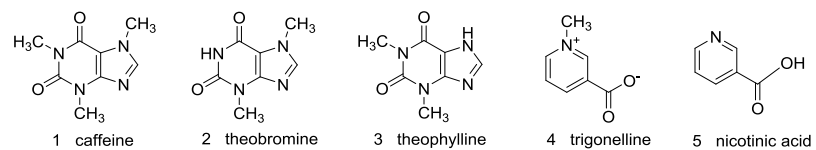

\section{Flavonoids}

Flavonoids and their glycosides are widely present in the leaves of $C$. arabica L. They are classified into different groups including catechins, anthocyanin, myricetin, fisetin, patuletin, luteolin, apigenin and quercetin. Ratanamarno et al. ${ }^{[5]}$ reported that catechin $(C, 6)$, epicatechin $(E C, 7)$, epicatechin gallate (ECG, 8) and epigallocatechin gallate (EGCG, 9) in fresh $C$ arabica L. leaves. Chen et al. identified delphinidin 3,5-diglucoside (10) and delphinidin 3-(6"-malonyl-glucoside) (11) in the young leaves of $C$. arabica L. ${ }^{[6]}$ Besides the above mentioned constituents, flavonoids and their glycosides were also isolated from the leaves of $C$. arabica L., which were named as cyanidin-3-O-Glu (12), cyanidin-3-O- rutinoside (13), kaempferol (14), kaempferol-3-O-Glc (15), kaempferol-3-O-Glc-Hex-DeHex (16), kaempferol-3-O-Glc-Hex (17), kaempferol-3-O-Glc-(6"- $R$ ha) (18), quercetin (19), quercitrin (20), isoquercitrin (21), rutin (22), hyperoside (23), quercetin-3-O-Glc-Hex-DeHex (24), quercetin-3-O-Glu (25), luteolin (26), patuletin (27), fisetin (28), myricetin (29) and apigenin (30). ${ }^{[6-9]}$ Their structures are shown in Figure 2.

\section{Terpenes}

Terpenes are another type of characteristic constituents in C. arabica L. 55 terpenes include the skeletons of ent-kaurane kahweol, villanovane diterpenoid, ent-kaurane diterpenoid glucosides, dammarane and pentacyclic triterpene. These terpenes were identified ursolic acid $(\mathbf{3 1}),{ }^{[6]}$ caffruone A-D $(32-35),{ }^{[10]}$ caffruenol $A-B(36-37),{ }^{[11]}$ caffruolide $A-B$ (38-39) ${ }^{[11]}$ tricalysiolide A-E (40-43), ${ }^{[11]} 16 \alpha, 17$-dihydroxyent-kauran-19-al (44), ${ }^{[11]}$ 16 $\beta$-17-hydroxy-ent-kauran-19-oic acid (45), ${ }^{[11]} 16 \alpha, 17$-dihydroxy-ent-kauran-19-oic acid $(46),{ }^{[11]}$ $9 \beta, 16 \alpha, 17$-trihydroxy-ent-kauran-19oic acid (47), ${ }^{[11]} 16 \beta-7,17-$ dihydroxy-ent-kauran-19-oic-methyl ester (48), ${ }^{[11]} 16 \alpha, 17$-dihydroxy-9(11)-ent-kauren-19-oic acid $(49),{ }^{[11]}(2 \beta, 4 \beta, 15 \alpha)-15$ hydroxy-2-\{[2-O-(3-methyl-1-oxo-butyl)]- $\beta$ - $D$-glucopyrnosyl]oxy\}-18-nor-ent-kaur-16-en-18-oic acid $(50),{ }^{[11]}$ caffarolide A-H $(51-58),{ }^{[12]}$ mascaroside $\mathrm{L} \| \mathrm{I}(59-60),{ }^{[13]}$ paniculoside $\mathrm{VI}$ $(61),{ }^{[13]}$ cofaryloside I (62), ${ }^{[13]}$ villanovane I (63), ${ }^{[13]}$ mozambioside (64), ${ }^{[13]}$ bengalensol (65), ${ }^{[13]}$ 19-norkaur-16-en-18-oic

Figure 1 Alkaloids isolated from C. arabica L. 


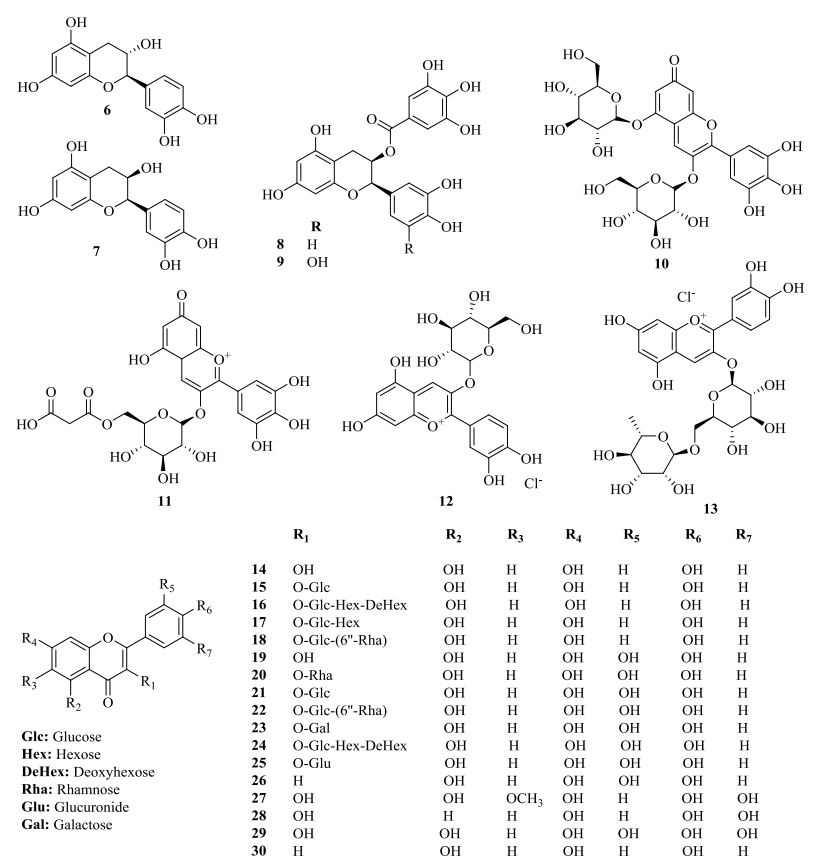

Figure 2 Flavonoids isolated from $C$. arabica $\mathrm{L}$.

acid-15-hydroxy-2-[[2-O-(3-methyl-1-oxobutyl)- $\beta$ - $D$-glucopyran-

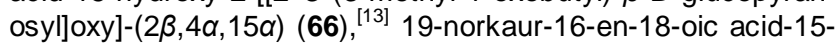
hydroxy-2-[[2-O-(3-methyl-1-oxobutyl)- $\beta$ - $D$-glucopyranosyl]oxy] - $(2 \beta, 4 \beta, 15 \alpha)(67),{ }^{[13]} 19-$ norkaur-16-en-18-oic acid-2-[[3-O- $\beta$ - $D$ glucopyranosyl-2-O-(3-methyl-1-oxobutyl)- $\beta$ - $D$-glucopyranosyl] oxy]-15-hydroxy- $(2 \beta, 4 \alpha, 15 \alpha)$ (68), ${ }^{[13]} 2 \beta, 16 \alpha, 17$-trihydroxy-entkauran-19-oic acid (69), ${ }^{[13]}$ paniculoside IV $(70),{ }^{[14]}$ mascaroside III-V (71-73), ${ }^{[14]} 20$-nor-cofaryloside I-II (74-75), ${ }^{[14]}$ villanovane $(76),{ }^{[14]}$ tricalysione $A(77),{ }^{[14]} 2 \beta, 16,17$-trihydroxyent-kauran-19-oic acid (78), 2-O-(2-O-isovaleryl- $\beta$ - $D$-glucopyranosyl)-4-atractyligenin $(79),{ }^{[14]} 2-O-(2-O$-isovaleryl- $\beta$ - $D$ gluco-pyranosyl)-4 $\beta$-atrac-tyligenin $(80),{ }^{[14]} 3-O-\beta$ - $D$-glucopyranosyl-2-O-(2-O-isovaleryl- $\beta$ - $D$-glucopyranosyl)- $4 \beta$ atracty ligenin $(\mathbf{8 1}),{ }^{[14]}$ kahweol $(\mathbf{8 2}),{ }^{[6]}$ cafestol $(\mathbf{8 3}),{ }^{[6]}$ 16-O-methylcafestol $(\mathbf{8 4})^{[6]}$ and ent-kaurane diterpenoid (85). ${ }^{[6]}$ Their structures are shown in Figure 3.

\section{Phenolic acids and their derivatives}

Phenolic acids and their derivatives from coffee main include mono-, di-caffeoylquinic acid and feruloylquinic acid, $p$-coumaroylquinic acid and their methyl esters. Asamenew et al. ${ }^{[15]}$ identified 57 phenolic acids from 19 green and roasted coffee beans by UPLC (Figure 4), which were identified as vanillic acid (86), benzoic acid (87), $p$-hydroxybenzoic acid (88), 3-hydroxybenzoic acid (89), gentosic acid (90), protocatechuic acid (91), caffeic acid (92), sinapic acid (93), p-coumaric acid (94), caftaric acid (95), 3-O-p-coumaroylquinic acid (96), 5-O-p-coumaroylquinic acid (97), 4-O-p-coumaroylquinic acid (98), 3-O-caffeoylquinic acid (99), 4-O-caffeoylquinic acid (100), 4-O-caffeoylquinic acid (101), 1-O-caffeoylquinic acid (102), 3-O-caffeoylquinic acid methyl ester (103), 5-O-caffeoylquinic acid methyl ester (104), 3,4-di-O-caffeoylquinic acid (105), 3,4-di-O-caffeoylquinic acid (106), 4,5-di-O-caffeoylquinic acid (107), 3,4-di-O-caffeoylquinic acid methyl ester (108), 3,5-di-Ocaffeoylquinic acid methyl ester (109), 4,5-di-O-caffeoylquinic acid methyl ester (110), 3-O-feruloylquinic acid (111), 4-O-feruloylquinic acid (112), 5-O-feruloylquinic acid (113), 1-O-feruloylquinic acid methyl ester (114), 3-O-feruloylquinic acid methyl ester (115), 5-O-feruloylquinic acid methyl ester
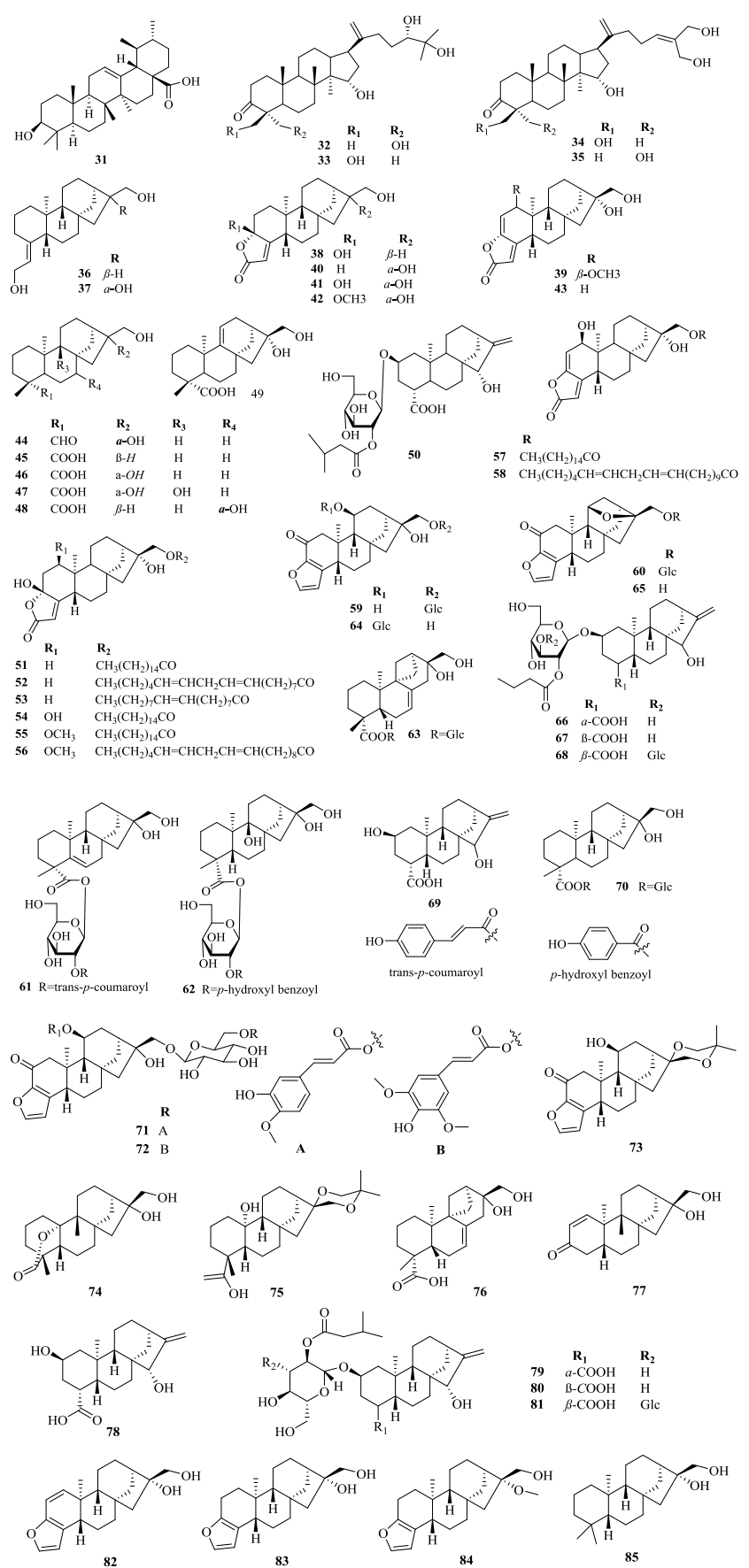

Figure 3 Terpenes isolated from C. arabica L.

(116), 3-O-feruloyl-5-O-caffeoylquinic acid (117), 3-O-feruloyl-4$O$-caffeoylquinic acid (118), 4-O-feruloyl-5-O-caffeoylquinic acid (119), 3-O-caffeoyl-4-O-feruloylquinic acid (120), O-feruloylquinic acid (121), 4-O-caffeoyl-5-O-feruloylquinic acid (122), 3-O-feruloyl-4-O-p-coumaroylquinic acid (123), 3-O-p-coumaroyl-5-O-feruloyl quinic acid (124), 4-O-p-coumaroyl-5-O-caffeoylquinic acid (125), caffeoyl- $N$-tryptophan (126), 5-O-caffeoyl-1,3 -quinide (127), 3-O-caffeoyl-1,5-quinide (128), 4-O-caffeoyl-1,33-quinide (129), 5-O-caffeoyl-1,4-quinide (130), 4-O-caffeoyl1,5-quinide (131), 3-O-feruloyl-1,5-quinide (132), 3,4-di-Ocaffeoyl-1,5-quinide (133), 4,5-di-O-caffeoyl-1,3-quinide (134), 3-O-caffeoyl-4-O-3-methylbutanoylquinic acid (135) and 3-Ocaffeoyl-4-O-3-methylbutanoyl-1,5-quinide (136). 


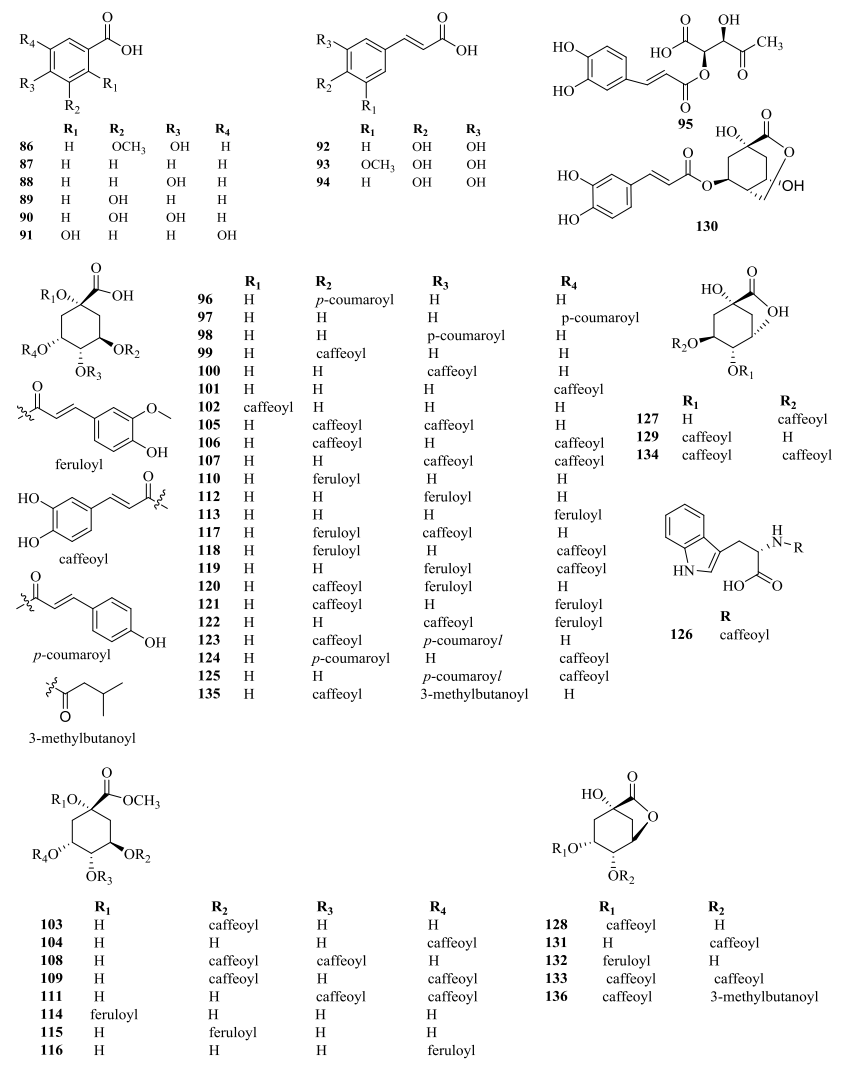

Figure 4 Phenolic acids and their derivatives isolated from $C$. arabica $\mathrm{L}$.
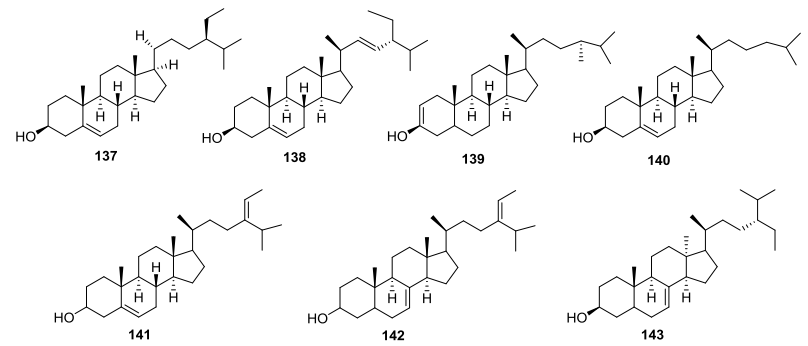

Figure 5 Sterols isolated from C. arabica L.

\section{Sterols}

There are 7 sterols isolated from C. arabica L. (Figure 5), named $\beta$-sitosterol (137), stigmasterol (138), campesterol (139), cholesterol (140), $\Delta 5$-avenasterol (141), $\Delta 7$-avenasterol (142), and delta-7-stigmastenol (143). ${ }^{[4]}$

\section{Flavor compounds}

There are 28 kinds of characteristic flavor substances in coffee, including aldehydes, alcohols, ketones, esters, pyrazines, guaiacol, vanillin, and so on. Hafsah et al. ${ }^{[16]}$ identified 101 volatile compounds regarding the metabolites from flowers and 72 from the skin pulp, green beans and peaberry green beans of the robusta coffee plant by gas chromatography-mass spectrometry (GC-MS).

\section{Other compounds}

Other types of compounds were isolated from $C$. arabica $\mathrm{L}$. (Figure 6), named as mangiferin (144), ${ }^{[17]}$ isomangiferin (145) ${ }^{[6]}$ scopoletin (146), ${ }^{[6]}$ a-carotene $(147),{ }^{[6]} \beta$-carotene $(148),{ }^{[6]}$ neoxanthin $(\mathbf{1 4 9}),{ }^{[6]}$ lutein $(\mathbf{1 6 0}),{ }^{[6]}$ violaxanthin $(\mathbf{1 5 1}),{ }^{[6]}$ antheraxanthin (152) ${ }^{[6]}$ and zeaxanthin (153) ${ }^{[6]}$

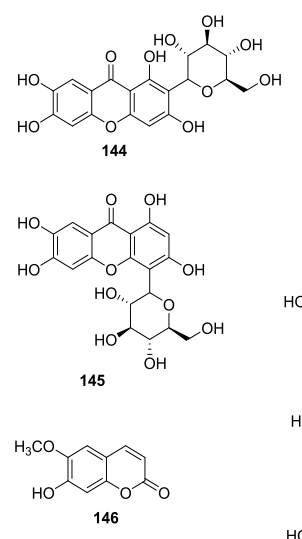

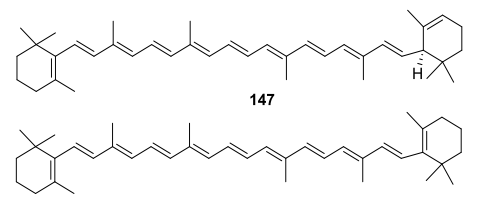

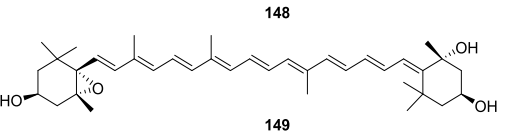<smiles>CC(C)=CC=CC(C)=CC=CC1(C)C(C)CC(O)C(C)C1C</smiles>

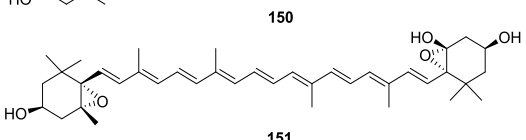

151<smiles>CCC(C)CC=CC(C)=CC=CC(C)=CC=CC(C)=CC=CC(C)=CCC1(C)C(C)CC(O)CC1C</smiles>

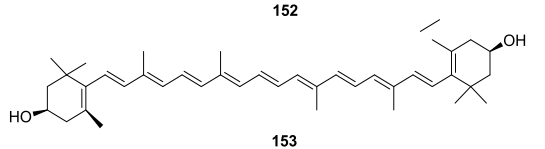

Figure 6 Other compounds isolated from C. arabica L.

\section{Bioactivities}

The pharmacological study on $C$. arabica $\mathrm{L}$. revealed that the crude extracts and pure compounds showed a wide range of biological activities, including antioxidation activity, anti-inflammatory activity, antitumor activity, antidiabetic activity, live protection activity, and neuroprotective activity.

\section{Antioxidation activity}

Zhang et al. ${ }^{[9]}$ evaluated the antioxidant capacities of the extracts from $C$. arabica $L$. by the scavenging $\mathrm{DPPH}$ and ABTS $^{+}$. The $\mathrm{IC}_{50}$ values of scavenging $\mathrm{DPPH}$ free radical and $\mathrm{ABTS}^{+}$were 1.082 and $1.085 \mathrm{mg} / \mathrm{mL}$, respectively. Samuchaya et $a l^{[18]}$ found that the methanolic extract from leaves of $C$. arabica L. showed high antioxidant activity. Total antioxidant activity was significantly associated with drying and maturity, fresh young $(92.93 \pm 0.51 \%)$, fresh mature $(92.24 \pm 0.95 \%)$, dried young $(95.01 \pm 0.44 \%)$, dried mature $(93.40 \pm 0.70 \%)$, respectively. The methanolic extract from green beans of $C$ arabica $\mathrm{L}$. in the DPPH test showed an $\mathrm{IC}_{50}$ value of 86.14 $\mu \mathrm{g} / \mathrm{mL} .^{[19]}$ The methanolic extract from green beans of $C$. arabica $\mathrm{L}$. in the DPPH test showed an $\mathrm{IC}_{50}$ value of 86.14 $\mu \mathrm{g} / \mathrm{mL} .^{[19]}$

\section{Anti-inflammatory activity}

The topical anti-inflammatory activity (carrageenan-induced paw oedema) of an ointment prepared using a methanolic extract from green beans of $C$. arabica L. histology was evaluated. ${ }^{[19]}$

\section{Antitumor activity}

According to a new study by Ei-Garawani, apoptotic anticancer pathway of the green and roasted $C$. arabica $\mathrm{L}$. aqueous extracts combined with VC was examined on the cancerous MCF-7 cell line and normal human lymphocytes. ${ }^{[20]}$

\section{Antidiabetic activity}

Sake et al. ${ }^{[21]}$ found that $C$. arabica L. bean and leaf extract showed a high decrease in blood glucose levels compared to the control group. Mellbye et al. ${ }^{[2]}$ found cafestol could increase glucose-stimulated insulin secretion in vitro and increase glucose uptake in human skeletal muscle cells. Cafestol increased insulin secretion from isolated islets by $75 \%-87 \%$ 
compared to the control group. Liu et al. ${ }^{[23]}$ found that trigonelline had protective efficiency on type 2 diabetes and diabetic peripheral neuropathy by decreasing blood glucose. Ginsenoside Rb1 and trigonelline could prevent the development of diabetic renal lesions by regulating the expression of miR-3550 and further associating with the Wnt/ $\beta$-catenin signaling. ${ }^{[24]}$

\section{Live protection activity}

Wiltberger et al. ${ }^{[25]}$ reported that coffee consumption is associated with a decreased risk of hepatocellular carcinoma recurrence and provides for increased survival following orthotopic liver transplantation. Multivariate analysis showed that coffee intake emerged as a major factor of hazard reduction for overall survival postoperative. Vitaglione et al. ${ }^{[26]}$ reported that coffee consumption could reduce high-fat diet-induced liver macrovesicular steatosis and serum cholesterol, alanine aminotransferase and glucose.

\section{Neuroprotective activity}

Ishida et al. ${ }^{[27]}$ found that 5-caffeoylquinic acid, one of the primary coffee polyphenols, was determined degraded $A \beta$ fibrils. ${ }^{[27]}$ Zeitlinet et al. ${ }^{[28]}$ confirmed caffeine shifted the balance between neurodegeneration and neuronal survival toward the stimulation of pro-survival cascades and inhibited pro-apoptotic pathways in the striatum and/or cortex to against AD. Using a MPTP neurotoxin model of PD, Chen et al. ${ }^{[29]}$ confirmed that caffeine might protect against $\mathrm{PD}$ and $\mathrm{PD}$-like features by stabilizing the BBB in part. The combination of theanine plus caffeine as a neuroprotective potential effect. ${ }^{[0]}$ Trigonelline has a potential therapeutic effect on the heart tissue of colitis and a neuroprotective effect, which can improve cognition and alleviate neuronal loss. ${ }^{[31,32]}$

\section{Conclusion and Perspective}

In summary, C. arabica L. is widely distributed in Yunnan province in China as a high medicinal value plant. With the improvement of modern instruments and experimental techniques, many chemical constituents have been isolated from C. arabica L. including alkaloids, flavonoids, terpenes, phenolic acids and their derivatives, sterols, flavor compounds and other compounds. The diversity of its chemical ingredients leads to a wide range of pharmacological activities such as antioxidation, anti-inflammatory, antitumor, antidiabetic, live protection, and neuroprotective activities. It should be pointed out that the researchers are mainly focused on finding compounds in C. arabica L., but they do not conduct in-depth research on the mechanism of their action. Therefore, for more rationally and effectively to develop resources in $C$. arabica L., researchers should perform further research on its chemical constituents, bioactivities and the mechanism of action in the future.

\section{Acknowledgement}

This work was supported by the National Natural Science Foundation of China-Yunnan Joint Fund (CN) (No. U1902206) and the National Nature Science Foundation of China (Nos. 21602196, 31960075).

\section{Conflict of Interest}

The authors declare no conflict of interest.

Copyright (C) 2020 Xiao-Jing Shen, Zhu-Bin Zhou, Fan-Qiu Nie, Cheng-Ting Zi, and Jiang-Ping Fan. This article is an open access article distributed under the terms and conditions of the Creative Commons Attribution (CC BY) license (http://creativecommons.org/ licenses/by/4.0/). The use, distribution or reproduction in other forums is permitted, provided the original author(s) or licensor are credited and that the original publication in this journal is cited, in accordance with accepted academic practice. No use, distribution or reproduction is permitted which does not comply with these terms.

\section{References}

[1] Wintgens, J. N. The Coffee Plant. In Coffee: Crowing, Processing, Sustuinuchle Production, Weinheim, 2004, pp. 1-14.

[2] Davis, A. P.; Tosh, J.; Ruch, N.; Fay, M. F. Growing coffee: Psilanthus (Rubiaceae) subsumed on the basis of molecular and morphological data; implications for the size, morphology, distribution and evolutionary history of coffea. Bot. J. Linn. Soc. 2011, 167, 357-377.

[3] Petermann, J. B.; Baumann, T. W. Metabolic Relations between Methylxanthines and Methyluric Acids in Coffea L. Plant Physiol. 1983, 73, 961-964.

[4] Qiu, M. H.; Zhang, Z. R.; Li, Z. R.; Zhou, L.; Chu, R.; Liu, J. Q.; Wang, W. H. Review of research on the chemical constituents and bioactivities of coffee. Plant Dcience J. 2014, 32, 540-550.

[5] Ratanamarno, S.; Surbkar, S. Caffeine and catechins in fresh coffee leaf (Coffea arabica) and coffee leaf tea. Maejo Int. J. Sci. Technol. 2017, 11, 211-218.

[6] Chen, X. M. A review on coffee leaves: phytochemicals, bioactivities and applications. Crit. Rev. Food Sci. Nutr. 2019, 59, 1008-1025.

[7] Júnior, A. P. D.; Shimizu, M. M.; Moura, J. C. M. S.; Catharino, R. R.; Ramos, R. V. R.; Ribeiro, R. V.; Mazzafera, P. Looking for the physiological role of anthocyanins in the leaves of coffea arabica. Photochem. Photobiol. 2012, 88, 928-937.

[8] Patay, E. B.; Bencsik, T.; Papp, N. Phytochemical overview and medicinal importance of coffea species from the past until now. Asian Pac. J. Trop. Med. 2016, 9, 1127-1135.

[9] Zhang, Y. H.; Fu, X. P.; Liang, W. J.; Han, Z. H.; Liu, S. Y.; Yuan, W.; Fan, J. P. Antioxidant activity and composition of anthocyanins of crude extracts from Yunnan arabica coffee husk. Food Sci. Technol. 2016, 41, 219-223.

[10] Wang, X.; Peng, X. R.; Lu, J.; Hu, G. L.; Qiu, M. H. New Dammarane Triterpenoids, Caffruones A-D, from the Cherries of Coffea arabica. Nat. Prod. Bioprospect. 2018, 8, 413-418.

[11] Wang, X.; Peng, X. R.; Lu, J.; Hu, G. L.; Qu, M. H. Ent-kaurane diterpenoids from the cherries of Coffea arabica. Fitoterapia 2019, 132, 7-11.

[12] Wang, X.; Meng, Q. Q.; Peng, X. R.; Hu, G. L.; Qu, M. H. Identification of new diterpene esters from green Arabica coffee beans, and their platelet aggregation accelerating activities. Food Chem. 2018, 263, 251-257.

[13] Shu, Y.; Liu, J. Q.; Peng, X. R.; Wan, L. S.; Zhou, L.; Zhang, T. Characterization of Diterpenoid Glucosides in Roasted Puer Coffee Beans. J. Agr. Food Chem. 2014, 62, 2631-2637.

[14] Chu, R.; Wan, L. S.; Peng, X. R.; Yu, M. Y.; Zhang, Z. R.; Zhou, L.; Li, Z. R.; Qiu, M. H. Characterization of New Ent-kaurane Diterpenoids of Yunnan Arabica Coffee Beans. Nat. Prod. Bioprospect. 2014, 6, 217-223.

[15] Asamenew, G.; Kim, H. W.; Lee, M. K.; Lee, S. H.; Lee, S. J.; Cha, Y. S.; Lee, S. H.; Yoo, S. M.; Kim, J. B. Comprehensive characterization of hydroxycinnamoyl derivatives in green and roasted coffee beans: A new group of methyl hydroxycinnamoyl quinate. Food Chem. 2019, X2, 100033.

[16] Hafsah, H.; Iriawati, I.; Syamsudin, T. S. Dataset of volatile compounds from flowers and secondary metabolites from the skin pulp, green beans, and peaberry green beans of robusta coffee. Data in Brief 2020, 29, 105219.

[17] Acidri, R.; Sawai, Y.; Sugimoto, Y.; Handa, T.; Sasagawa, D.; Masunaga, T.; Yamamoto, S.; Nishihara, E. Phytochemical Profile and Antioxidant Capacity of Coffee Plant Organs Compared to Green and Roasted Coffee Beans. Antioxidants 2020, 9, 1-18. 
[18] Ngamsuk, S.; Huang, T. C.; Hsu, J. L. Determination of Phenolic Compounds, Procyanidins, and Antioxidant Activity in Processed Coffea arabica L. Leaves. Foods 2019, 8, 1-13.

[19] Perolizzi, S.; D’Angelo, V.; Aragona, M.; Dugo, P.; Cacciola, F.; Capillo, G.; Dugo, G.; Lauriano, E. R. Nat. Prod. Res. 2018, 3, 1-7.

[20] El-Garawani, I. M.; El-Nabi, S. H.; El-Shafey, S.; Elfiky, M.; Nafie, E. Coffea arabica Bean Extracts and Vitamin C: A Novel Combination Unleashes MCF-7 Cell Death. Curr. Pharm. Biotechnol. 2020, 21, 23-36.

[21] Martina, S. J.; Govindan, P. A.; Wahyuni, A. S. The Difference in Effect of Arabica Coffee Gayo Beans and Leaf (Coffea Arabica Gayo) Extract on Decreasing Blood Sugar Levels in Healthy Mice. Open Access Macedonian J. Med. Sci. 2019, 7, 3363-3365.

[22] Mellbye, F. B.; Jeppesen, P. B.; Shohouh, P.; Lausten, C.; Hermansen, K.; Gregersen, S. Cafestol, a bioactive substance in coffee, has antidiabetic in KKAy mice. J. Nat. Prod. 2017, 80, 2353-2359.

[23] Liu, L.; Du, X.; Zhang, Z.; Zhou, J. Y. Trigonelline inhibits caspase 3 to protect $\beta$ cells apoptosis in streptozotocin-induced type 1 diabetic mice. Eur. J. Pharmacol. 2018, 836, 115-121.

[24] Shao, X. N.; Chen, C.; Miao, C. S.; Yu, X. Y.; Li, X. J.; Geng, J. N.; Fan, D. Y.; Lin, X. Y.; Chen, Z.; Shi, Y. Expression analysis of microRNAs and their target genes during experimental diabetic renal lesions in rats administered with ginsenoside $\mathrm{Rb} 1$ and trigonelline. Pharmazie 2019, 74, 492-498.

[25] Wiltberger, G.; Wu, Y.; Lange, U.; Hau, H. M.; Tapper, E.; Krenzien, F.; Atanasov, G.; Benzing, C.; Feldbrügge, L.; Csizmadia, E.; Broschewitz, J.; Bartels, M.; Seehofer, D.; Jonas, S.; Berg, T.; Hessel, P.; Ascherl, R.; Neumann, U. P.; Pratschke, J.; Robson, S. C.; Schmelzle, M. Protective effects of coffee consumption following liver transplantation for hepatocellular carcinoma in cirrhosis. Aliment. Pharm. Ther. 2019, 49, 779-788.

[26] Vitaglione, P.; Mazzone, G.; Lembo, V.; D'Argenio, G.; Rossi, A.;
Guido, M.; Savoia, M.; Salomone, F.; Mennella, I.; Filippis, F. D.; Ercolini, D.; Caporaso, N.; Morisco, F. Coffee prevents fatty liver disease induced by a high-fat diet by modulating pathways of the gut-liver axis. J. Nutr. Sci. 2019, 8, 1-11.

[27] Ishida, K.; Yamamoto, M.; Misawa, K.; Nishimura, H.; Misawa, K.; Ota, N.; Shimotoyodome, A. Coffee polyphenols prevent cognitive dysfunction and suppress amyloid $\beta$ plaques in APP/PS2 transgenic mouse. Neurosci. Res. 2019, 154, 35-44.

[28] Zeitlin, R.; Patel, S.; Burgess, S.; Arendash, G. W.; Echeverria, V. Caffeine induces beneficial changes in PKA signaling and JNK and ERK activities in the striatum and cortex of Alzheimer's transgenic mice. Brain Res. 2011, 1417, 127-136.

[29] Chen, X.; Lan, X.; Roche, I.; Liu, R.; Geiger, J. D. Caffeine protects against MPTP-induced blood-brain barrier dysfunction in mouse striatum. J. Neurochem. 2008, 107, 1147-1157.

[30] Sun, L.; Tian, X.; Gou, L.; Ling, X.; Wang, L.; Feng, Y.; Xing Y, X.; $\mathrm{Liu}, Y$. Beneficial synergistic effects of concurrent treatment with theanine and caffeine against cerebral ischemia reperfusion injury in rats. Can. J. Physiol. Pharm. 2013, 91, 562-569.

[31] Omidiardali, H.; Lorigooini, Z.; Soltani, A.; Balali-Dehkordi. S.; Amini-Khoei, H. Inflammatory responses bridge comorbid cardiac disorder in experimental model of IBD induced by DSS: protective effect of the trigonelline. Inflammopharmacology 2019, 27, 1265-1273.

[32] Fahanik, B. J.; Baluchejadmojarad, T.; Nikbakht, F.; Roghani, M. Trigonelline protects hippocampus against intracerebral $A \beta(1-40)$ as a model of Alzheimer's disease in the rat: insights into underlying mechanisms. Metab. Brain Dis. 2019, 34, 191-201.

Received June 10, 2020 Accepted July 20, 2020 